\title{
Translation of Idioms and Fixed Expressions: Strategies and Difficulties
}

\author{
Amir Shojaei \\ Department of English, Quchan Branch, Islamic Azad University, Quchan, Iran \\ Email: amir_shojaei66@yahoo.com
}

\begin{abstract}
This research tries to investigate and identify firstly some existing obstacles in the process of translating inter-lingual idiomatic pairs, and then to suggest some weighty theoretical strategies to overcome such difficulties. Following Mona Baker's (1992) classification of difficulties and strategies and the related subcategories mentioned, the present study makes an effort to analyze such classifications and practically apply them largely for some English and the equivalent Turkish (Azeri) as well as Persian pairs. Findings show that there are a number of factors which should be considered in order to translate idiomatic expressions correctly. The most important of such factors include socio-linguistic elements, cultural aspects, linguistic and stylistic considerations as well as some specific meta-lingual factors.
\end{abstract}

Index Terms-idioms, fixed expressions, idiomatic translation, Baker, difficulties, strategies

\section{INTRODUCTION}

Idioms and fixed expressions are an inalienable part of each language found in large numbers in most of the languages. Since the meaning of these collocations can not be understood from the superficial meanings of the single words constituting them, so there are some problems in both processes of understanding and translating them.

The process of translating idioms and fixed expressions from one language into another is a fine work which obliges a translator to have a good knowledge of both languages and cultures being shared or transferred as well as being able to identify and cope with the contingent problems in the process of finding an efficient equivalent for the inter-lingual idiomatic pairs. People of different languages use completely different expressions to convey a similar meaning, in a way that while an expression might be completely tangible and easy-to-understand for the interlocutors of a specific language, the same set of words and expressions may seem fully vague and dim and even in some cases nonsense to the speakers of the other. This originates in the fact that each language has got some culture-specific items that are completely different from the corresponding items in another language. Besides, there are some differences in such factors as religion, geographical locations, different ideologies, and social classes of languages and societies that harden the process of understanding and translating idiomatic pairs from one language into another. Hence, there are two main problems in this case: 1) How to understand the meaning of idioms and fixed expressions of a specific language; and 2) How to recreate the same sets of idioms and fixed expressions of one language in another language in a way that they might convey exactly the same ideas of the original language.

This research aims to investigate what difficulties arise in the two processes of interpreting and translating idioms and fixed expressions from one language into another. An attempt has been made to exemplify the difficulties and strategies regarding this phenomenon so that a pseudo-descriptive list of existing difficulties might be declared for the readers and translators of such expressions. At the same time some quasi-prescriptive categories of strategies and solutions to cope with those problems have been mentioned largely based on Mona Baker's equivalence above word level' (1992, pp. 68-71) classification of difficulties and strategies for translating idiomatic expressions. Considering these two classifications and the sub-categories of each group this study tries to show some guidelines for both the readers and translators of idiomatic expressions in the process of translating such concepts. Some practical examples of English and Turkish (Azeri) as well as some Persian collocations will be declared throughout the body of the paper. Firstly, the difficulties in the processes of understanding the meanings of idioms will be analyzed, then the possible ways of solving those difficulties will be mentioned mainly through applying those strategies proposed by Baker (1992) in her book, In other Words, alongside some other experimental findings mentioned by a number of experienced translators and scholars. Besides, a number of suggestions, regarding idiomatic translation, made by such scholars as Newmark (1988), Fernando (1996) and Gottlieb (1997) will be taken into consideration.

\section{IDIOMS AND FIXED EXPRESSIONS}

As a matter of fact there are so many languages all around the world each of which differs from the others in some aspects. Also it is obvious that the people of different countries have got diverse ideologies and every society perceives the world in a different way from the other one and consequently the ideologies influence the languages and the ways of 
expressing meanings. Finally, as the result, the collocations and idiomatic expressions of the languages diverge from each other in most cases.

The previous works done by some other researchers include Noor Balfaqeeh's (2009) and Margarita Strakšiene's (2009) papers on the issue. Balfaqeeh uses a number of theories regarding this issue beside mentioning some Arabic examples by making a questionnaire and providing some quantitave and qualitative data. On the other hand Strakšiene analyzes idiomatic expressions through giving some Lithuanian examples and concludes that the translation of idioms involves four basic translation strategies:

"paraphrasing, which involves explanatory and stylistic paraphrase; idiom to idiom translation, which involves using idiom of similar meaning and form, and using idiom of similar meaning but dissimilar form; literal translation; and finally omission" (Strakšiene, 2009, p. 18).

To illuminate the issue we need to explain some types of meaning at first.

\section{A. Definition of Idioms \& Fixed Expressions}

Idioms and fixed expressions have got a vast territory in a way that they can include many cultural aspects such as religious beliefs, culture-specific items, superstitions, and different ideologies of the people from diverse societies and nations.

Idioms are treated as figures of speech, which are defined in the Collins English Dictionary (2006) as "an expression such as a simile, in which words do not have their literal meaning, but are categorized as multi-word expressions that act in the text as units". Longman Idioms Dictionary (1998) defines them as "a sequence of words which has a different meaning as a group from the meaning it would have if you understand each word separately". Accordingly, idioms should not be broken up into their elements because they are sometimes referred to as a fixed expression (Cowie and Mackin, 1975, viii cited in Balfaqeeh, 2009).

Newmark (1988, p. 104) who considers idiom as an 'extended' metaphor claims that an idiom has two main functions: pragmatic and referential. The pragmatic function is to appeal to the senses, to interest, to surprise, to delight. He mentions that the first function is called cognitive, while the other is aesthetic. The referential function is "to describe a mental process or state, a concept, a person, an object, a quality or an action more comprehensively and concisely than is possible in literal or physical language" (Cited in Strakšiene, 2009, p. 14).

According to McMordiew "we can say that an idiom is a number of words which [when they are] taken together, mean something different from the individual words of the idiom when they stand alone". (McMordiew, 1983, p. 4)

On the other hand Moon (1998) in her book, A Corpus-Based Approach, defines idiom as "an ambiguous term, used in conflicting ways"'. In lay or general use, idiom has two main meanings. First, idiom is a particular means of expressing something in language, music, art, and so on, which characterizes a person or group; secondly, an idiom is a particular lexical collocation or phrasal lexeme, peculiar to a language" (Moon, 1998, p. 3).

Most of the scholars quote that both idioms and fixed expressions and specially the former one in most of the cases show no flexibility to change in form and grammar. In this case Baker (1992) states that:

...idioms and fixed expressions are at the extreme end of the scale from collocations in one or both of these areas: flexibility of patterning and transparency of meaning. They are frozen patterns of languages which allow little or no variation in form and, in the case of idioms, often carry meanings which can not be deduced from their individual components (p. 63).

She also mentions that some idioms even allow "no variation in form under normal circumstances" and that a translator can not do any of the following with an idiom: a) Change the order of the words in it; b) Delete a word from it; c) Add a word to it; d) Replace a word with another; and finally e) Change its grammatical structure (idem).

Moreover, Carter (1998, p. 66) classifies idioms as a type of fixed expression that include proverbs, stock phrases, catchphrases, allusions, idiomatic similes and discoursal expressions. But Balfaqeeh (2009) criticizes that "this classification does not have defined boundaries and a structural overlap is very much expected" (pp. 5-6).

\section{B. Types of Meaning}

Different scholars of linguistics have categorized types of meaning in their own ways. Some of them have spoken in general terms while some others have used more specific classifications. For example, Larson (1984) believes that there are two primary kinds of meaning, namely, 'Explicit' and 'Implicit' meanings (p. 41). He states that there are also three sub-categories for these two primary kinds of meaning:

1) 'Referential meaning' in which a specific word "refers to a certain thing, event, attribution or relation which a person can perceive or imagine" (idem);

2) 'Organizational meaning' that deals some aspects with surface structure and grammatical points of the sentence in a way that "referential meanings are put together and expressed by a variety of combinations (idem);

3) 'Situational meaning' that is the meaning of an utterance in a given communication (ibid: 41-42).

On the other hand Nida (1964) categorizes three sub-branches for the kinds of meaning:

1) 'Linguistic meaning' that borrows some elements of Chomsky's (1957) model and the fact that meanings are arbitrary;

2) 'Referential meaning' that is called denotative meaning. This category contains the words that can be found as an entry of a dictionary; and finally; 
3) 'Emotive meaning' that is called connotative meaning and deals with extra-linguistic factors and the figurative meanings that a word may convey (cited in Munday, 2001, pp. 38-39).

The last classification of meaning types in this paper deals with Koller's (1979) equivalence or 'Korrespondenz and aquivalenz' (ibid: 46) in which he proposes five types of meanings for the corresponding equivalents:

1) 'Denotative equivalence' deals with non-linguistic content of a text and Koller names it as content invariance;

2) 'Connotative equivalence' deals with a feeling or idea that is suggested by a particular word although it is not necessarily a part of that word's meaning. Koller calls this type of meaning as stylistic equivalence;

3) 'Text-normative equivalence' is related to different text types in which different types of texts behave in different ways;

4) 'Pragmatic equivalence' which deals with the influence of the text on the target language audience. It can be said that this type of meaning is the same as Nida's (1964) 'dynamic equivalence';

5) 'Formal equivalence' that concentrates on "the form and aesthetics of the text and meaning" (idem). This kind of 'Formal equivalence' mustn't be considered as the same 'Formal equivalence' of Nida (1964) which refers to the literal meaning of a word.

As it can be seen every scholar has got his/her own way of categorizing meaning types that is based on his/her personal taste, but there is one thing in common and it is nearly all the scholars have determined a kind of meaning that deals with a meaning type related to 'non-linguistic' or 'extra-linguistic' aspects of words, i.e., all scholars have got a categorization which refers to idiomatic expressions of languages. For example in the meaning types stated above, Larson's (1984) 'situational meaning', Nida's (1964) 'emotive meaning' and Koller's (1979) 'connotative meaning' are related to the domain of idioms and fixed expressions.

\section{Baker's (1992) Contribution to Idioms and Fixed Expressions}

Baker (1992) looks at equivalence at a series of levels: at word, above-word, grammar, thematic structure, cohesion and pragmatic levels (Cited in Munday, 2001, p. 95). In this paper we are dealing with her 'Above-word' and 'Pragmatic' levels of equivalence because the realm of idioms and fixed expressions falls mainly into these two ones. In the case of first level Baker (1992) mentions that:

...words rarely occur on their own; they almost always occur in the company of other words. But words are not strung together at random in any language; there are always restrictions [difficulties] on the way they can be combined to convey meaning...It would seem, then, that the patterns of collocations are largely arbitrary and independent of meaning. This is so both within and across languages. The same degree of mismatch that can be observed when observing collocational patterns of synonyms and near-synonyms within the same language is evident in the collocational patterning of 'dictionary equivalents/near-equivalents' in two languages (pp. 47-8).

Moreover, she also discusses three pragmatic concepts where pragmatics is "the way utterances are used in communicative situation":

1. Coherence relates to the audience's understanding of the world, which may be different for ST (Source Text) and TT (Target Text) readers.

2. Presupposition is where the receiver of the message is assumed to have some prior knowledge.... This case arises problems in translation because TT readers may not have the same knowledge as ST readers. Possible solutions are rewording or footnotes.

3. Implicature is where the meaning is implied rather than stated.....this can lead to a mistranslation of the intention of the message (cited in Munday, 2009, pp. 97-98).

\section{Introducing Baker's Difficulties for the Translation of Idiomatic Expressions}

Baker (1992, p. 65) claims that "the first difficulty that a translator comes across is being able to recognize that s/he is dealing with an idiomatic expression".

She believes that some of the idiomatic expressions are recognized more easily than some other ones mentioning two situations in which an expression can be recognized easily:

1) When the idioms 'violate truth conditions', and

2) When the idioms include expressions which seem grammatically 'ill-formed'. And finally concludes that "the more difficult an expression is to understand and the less sense it makes in a given context, the more likely a translator will recognize it as an idiom" (idem).

Afterwards, Baker (ibid: 66) classifies two hard-to-be-recognized cases in which an idiom might be misinterpreted:

1) Some idioms are misleading, and

2) An SL (Source Language) idiom may have a very close counterpart in the TL (Target Language) which seems similar on the surface but has a totally or partially different meaning.

The difficulties mentioned in the last part were merely related to the problems in the process of interpreting idioms and fixed expressions and not the process of translating them. On her third chapter of her book Baker (1992) throughout the part and pages regarding difficulties of translating idiomatic expressions classifies these problems into four subcategories:

1) An idiom or fixed expression may have no equivalent in the target language. 
2) An idiom or fixed expression may have a similar counterpart in the target language, but its context of use may be different.

3) An idiom may be used in the source text in both its literal and idiomatic senses at the same time.

4) The very convention of using idioms in written discourse, the contexts in which they can be used, and their frequency of use may be different in the source and target languages (pp. 65-71).

Through the body of work an attempt will be made to explain these difficulties and problems in detail.

\section{E. Introducing Baker's Strategies to Overcome the Difficulties of Idiomatic Translation}

Although there are some difficulties in the process of translating idioms and fixed expressions, on the other hand there are some strategies to overcome such probable difficulties. Baker (1992) declares four problem-solving strategies on the third chapter of her book in numerous pages considering this issue as follows:

1) Using an idiom of similar meaning and form

2) Using an idiom of similar meaning but dissimilar form

3) Translation by paraphrase

4) Translation by omission (pp. 71-78).

Moreover, she states that:

"The way in which an idiom or a fixed expression can be translated into another language depends on many factors....Questions of style, register, and rhetorical effect must also be taken into consideration" (ibid: 71-72).

In addition, Fernando and Flavell (1981, p. 82) warn translators against "the strong unconscious urge in most translators to search hard for an idiom in the receptor language, however inappropriate it may be" (Cited in Baker, 1992, p. 72).

Finally, there is the typology of idioms proposed by Fernando (1996, p. 35) in which he distinguishes three subclasses of idioms:

1) Pure Idioms: 'a type of conventionalized, non literal multiword expression' (ibid: 36). Pure idioms are always non literal, however they may be either invariable or may have little variation. In addition, idioms are said to be opaque (ibid: 32),

2) Semi-idioms: 'semi-idioms are said to have one or more literal constituents and one with non literal sub sense'. Therefore, this type of idioms is considered partially opaque (ibid: 60), and

3) Literal idioms: 'this sub-class of idioms are either invariable or allow little variation'. In addition, literal idioms are considered to be transparent as they can be interpreted on the basis of their parts (Cited in Strakšiene, 2009, p. 14).

\section{Methodology}

The main source that has been the theoretical framework of the paper is Mona Baker's (1992) In Other Words and specifically the third chapter, Equivalence Above Word Level, which deals with idioms \& fixed expressions and some other ultra-word level textures such as proverbs and collocations. Therefore, most of the topics and headings of the data have been chosen based on the mentioned book. Besides, some pamphlets of translation studies for M.A. students were used to have some general knowledge on different theories as a whole. Wherever needed, some related articles have been extracted from the internet for further study so as to prevent any possible mistake in the materials being presented or claimed.

Throughout the paper it has been tried to mention the difficulties faced in the translation of idioms \& fixed expressions as well as providing some strategies and loopholes to overcome those obstacles in a descriptive-qualitative way. Another point to be mentioned is that some relevant Turkish (Azeri) and Persian exemplifications have been made in most of the cases for the materials presented in order that the ideas might be as transpicuous and tangible as possible.

The first step taken in the process of writing this paper included gathering some authentic data regarding the subject of the work. To gain information, firstly Mona Baker's (1992) In Other Words was studied in detail, and the parts of the book containing any relevant data in this issue were highlighted mainly focusing on the quotations or categorizations for idioms and fixed expressions. A large number of pamphlets and articles on this subject were collected for further reading and analysis too.

The next step was to find some works of previous researchers and scholars on the issue. Analyzing and exploring the found sources, some helpful theories and ideas were added to the paper so as to cover a comprehensive body of knowledge and data. Since this paper uses a descriptive method of writing and it is a library research, lots of examples and descriptions were extracted from a corpus of books and pamphlets to be worked on. In this way Baker's (1992) classification of difficulties and strategies to deal with idioms and fixed expressions was illustrated by supplementary examples of Turkish (Azeri) and Persian- and even in some cases other languages- so that there might be a body of reliable and safe strategies for the translators of idiomatic expressions to take in the process of 'decoding' an 'encoded' SL idiom in TL.

Finally, the last step was to collect the findings and mention the strategies that are adequate and efficient for the translation of idioms and fixed expressions from one language into another.

\section{PROCEDURE}


Although most idioms resist variation in form, some are more flexible than others. For example a BBC radio reporter once quoted a conference speaker as saying 'there was too much buck passing'. The common form of the idiom is 'pass the bucket' (refuse to accept responsibility for something). And yet, we would not expect to hear 'there was too much way giving' for 'give way' (allow someone to do something you disapprove of) (Baker and McCarthy cited in Baker, 1992, p. 64).

The mentioned example shows that we are not dealing with an extremist discussion of 100 percent acceptance or rejection and that there are some cases of exception as well.

Furthermore, regarding the direction of translation, The Code of Professional Ethics of the Translators' Guild of Great Britain states that:

A translator shall work only into the language (in exceptional cases this may include a second language) of which he has native knowledge. 'Native knowledge' is defined as the ability to speak and write a language so fluently that the expression of thought is structurally, grammatically and idiomatically correct (ibid: 65).

Throughout the next pages of the study the difficulties beside the strategies to gain such structurally, grammatically and idiomatically correctness will be analyzed.

\section{A. Translation of Idiomatic Expressions: Applying Difficulties}

Many scholars believe that the difficulties regarding idioms and fixed expressions are twofold:

1) How to know that we are dealing with an idiom in a given sentence; and

2) What are the obstacles to translate such items?

Considering this issue Baker (1992) puts:

The main problems that idiomatic and fixed expressions pose in translation relate to two main areas: the ability to recognize and interpret an idiom correctly; and the difficulties involved in rendering the various aspects of meaning that an idiom or a fixed expression conveys into the target language (p. 65).

She also believes that such difficulties are encountered largely in the case of idioms and NOT fixed expressions.

To clarify the point let's have an example. Suppose that a non-Persian translator is going to translate the following text from Persian into English:

\section{Source Text $\rightarrow$ Persian}

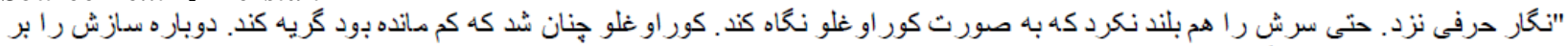

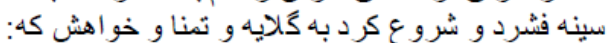

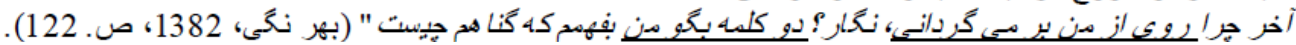

Target Text $\rightarrow$ English (Literal Translation)

Negar didn't utter any word. She even didn't raise her head to look at Koroĝli. Koroĝli was so sad as if he was going to cry. He held his Saz (musical instrument) closely to his chest uttering such words of complaining and supplication as:

Why do you return your face from me, Negar? Say two words to me until I know what my sin is (Translation by the researcher).

As it can be seen when a non-native speaker of Persian is reading the underlined parts of the ST s/he might have some difficulties in the process of understanding and consequently translating such expressions. Firstly s/he must recognize that $\mathrm{s} / \mathrm{he}$ is dealing with some idiomatic expressions that have got a figurative meaning, i.e., s/he must know that "روى از من بر مى كرد/نىى and "رو كلمه بكو" are two well-known fixed expressions in Persian. Then it is the time to interpret them correctly so as to prevent such nonsense and opaque translations as what were mentioned in this case. If the translator knew that s/he is dealing with some idiomatic expressions, and then if s/he interpreted them correctly, then the resulting correct translations would be:

Why do you disgrace me? And please speak to me.

Thus, based on Baker (1992) and as this example shows there are two kinds of difficulties regarding the translation of idiomatic expressions:

1) Difficulties in the process of interpreting idioms; and

2) Difficulties in the process of translating idioms.

\section{a. Difficulties in the Process of Interpreting Idioms}

The first difficulty that a translator comes across is that $\mathrm{s} / \mathrm{he}$ must know whether $\mathrm{s} / \mathrm{he}$ is dealing with an idiomatic expression in a given context or not. Sometimes recognizing an idiom is not an easy task. There are some sociolinguistic and semantic reasons beside some cultural ones for this claim.

Baker (1992, p. 65) considering this issue identifies different types of idioms and believes that some of these idioms are 'more easily recognizable than others' and cites three groups of such idioms:

1) Expressions which violate truth conditions; for instance, "آب كه سر بالو بره قورباغه /بوالعطا ميخونها" (Literally: when water goes up, the frog sings a song) or "آسمان ريسمون بافنت " (Literally: to weave sky and rope!) in Persian;

2) Expressions which seem ill-formed because they do not follow the grammatical rules of the language; for instance, "تها و توه قضيه رو درآوردن"(Literally: to extract the butt and bit of the story!) in Persian;

3) Expressions which start with like (simile-like structures) also tend to suggest that they should not be interpreted literally; for instance, "مثل گرك بارون ديذه /ست (Literally: like a rain-seen wolf!) in Persian. 
She (1992) also argues that, the very fact that s/he [the reader or translator] cannot make sense of an expression in a particular context will alert the translator [or reader] to the presence of an idiom of some sort, citing two situations in which an idiom can be easily 'misinterpreted' if the translator is not familiar with it:

1) Some idioms are 'misleading'; they seem transparent because they offer a reasonable literal interpretation and their idiomatic meanings are not necessarily signaled in the surrounding text.

2) An idiom in the source language may have a very close counterpart in the target language which looks 'similar on the surface' but has a totally or partially 'different meaning' (p. 66).

To clarify the point let's have some examples for each of these two cases:

"سر كسى شيره مالبين" is an idiom in Persian which literally means 'to curry syrup to someone's head'. This is a misleading idiom for a non-Persian interlocutor who doesn't have any background knowledge on the origin of this idiom as well as not being familiar with the connotative meaning it implies. Since literally it seems correct in Persian, the translator might be mislead and take merely the surface meaning of it ignoring the 'pragmatic function' (Newark, 1988) or 'sociolinguistic factors' (Ian Mason, 1990). On the other hand if s/he firstly had recognized the idiom and then interpreted it correctly, the resulting translation might have been: 'take someone for a ride'.

Considering the second case we can provide another example. Take the English fixed expression 'to give an exam' for instance. Literal translation of this expression into Persian is: "دنحان دادن" (Literally: to give an exam) which has got a completely different meaning from the English one; for the meaning of this expression in English is: "an agent such as a teacher gives a paper to the students to hold an exam" but the Persian counterpart implies exactly the opposite, i.e., "the agent like a student gets the paper to answer". This is also correct in the case of English and Turkish (Azeri) counterparts where the Turkish 'imtzhăn vermax' one (Literally: to give an exam) means the opposite (to take an exam) and 'imtzhăn almax' (Literally: to take an exam) implies the contrary (to give an exam). Baker (1992, p. 67) supplies another good example in this case where 'has the cat got your tongue' in English means 'to urge someone to answer a question or contribute to a conversation' but the French counterpart 'donner sa langue au chat' (to give one's tongue to cat) means 'to give up, for example when asked a riddle'. She also continues that:

"Idiomatic and fixed expressions have individual collocational patterns. They form collocations with other items in the text as single units and enter into lexical sets which are different from those of their individual words" (idem).

Here is another example from Persian where "مته به خشخاش كذاشتن" (Literally: to drill a poppy) means "to be over nice; split hairs' while neither "مته" (drill) nor "خشخاش" (poppy) has got any thing to do with the general idiomatic meaning of the whole collocational pattern.

After interpreting an idiomatic expression in a correct manner it is the time to translate it and find an efficient equivalent in the TL.

\section{b. Difficulties in the Process of Translating Idioms}

As a matter of fact the process of translating an idiomatic expression is more difficult than the process of interpreting it and every translator, even a tyro, verifies this claim. Furthermore, since the meaning of an idiom can not be deduced from the separate words that it consists of, then exactly for the same reason we can not recreate the same meaning merely by substituting a literal TL item for the SL one.

There are some primary problems the most prominent of which are related to the discussion of 'Equivalence'. In this regard Balfaqeeh (2009) mentions that:

"Idioms are difficult to translate. It is sometimes hard to find the right equivalent for a single word without finding equivalence for a sequence of words that convey one specific meaning" (p. 6).

It appears that there are some socio-linguistic factors for this claim. For example, idioms may have some culturespecific or culturally-bound items which cause some difficulties in the process of translating. In the case of culturallybound items Teilanyo (2007) stresses that:

"The difficulty arises from the problem of finding adequate target language equivalents for terms conveying culturesensitive notions in the source language as a result of the fact that the two languages have different meaning subsystems and cultures" (p. 16).

Now let's turn to the classification of difficulties expressed by Mona Baker (1992) through which she categorizes the main problems involved in translating idioms and fixed expressions into four sub-categories:

1. "An idiom or fixed expression may have no equivalent in the target language" (p. 68).

She also expresses that different languages view the world differently. This means that while a language might express a specific meaning using a single word, another language may express it by the use of a different linguistic means such as an idiom, a fixed expression or an explanatory sentence and vice versa. This occurs largely in the case of culture-specific items, whether they are single words with defined attributive meaning, or idioms and fixed expressions with opaque and dim meanings. For example, while the single word 'Baptize' is completely tangible for a Christian English audience, it a fully unknown and vague concept for a Turk or Persian Muslim requiring the translator to give such explanatory information as: "birini din yolünda yündurmağinan məsihiyət dininə gatirmax" (making a person Christian through a ritual bath) for an Azeri Turk, or "كسى را با غسل تعدي به دين مسيح وارد كردن" (making a person Christian through a ritual bath) for the Persian one. In other words, the translator should convey this meaning: "a Christian ceremony in which a person has water poured on their head, or is covered briefly in water, in order to show that they have become a member of the Christian Church". 
In this regard Baker (1992, p. 68) cites some other categories like 'fixed expressions with fixed formulae' including such examples as 'Merry Christmas' and 'Say when' or 'idioms with fixed formulae' such as 'Yours sincerely' and 'Yours faithfully'.

She finally concludes that we mustn't always expect to find 'equivalent idioms and fixed expressions' between languages. She mentions that: "Idioms and fixed expressions which contain culture-specific items are not necessarily

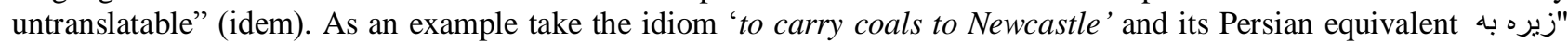
"To carry caraway to Kerman) in which the English idiom uses the city Newcastle as the reference or measure of abundance while the Persian one applies the city Kerman for this aim. Besides, the English idiom uses the material coal for which the Persian one applies "زيره" (Caraway). Furthermore Grauberg (1989) declares the German equivalent 'Eulen nach Athen tragen' (to carry owls to Athens) and the French one 'porter de l'eau a la riviere' (to carry water to the river) which approve the mentioned idea (cited in Baker, 1992, p. 69). There is also another example considering the idiom 'I'll say' where the Turkish equivalent uses 'ağziva qŭrban olum!' (thanks for your mouth!) and the Persian one applies "!" "آى كفنى" (you just told it!).

2. "An idiom or fixed expression may have a similar counterpart in the target language, but its context of use may be different" (idem); i.e., an SL item has got an exact TL counterpart but the usage or pragmatic functions of the two differ from each other.

Baker puts the English idiom 'to sing a different tune' that means "to say or do something that signals a change in opinion because it contradicts what one has said or done before" and compares it with the Chinese equivalent "changdui-tai-xi' (to sing different tunes/to sing a duet) mentioning that the Chinese one has 'strong political connotations' as well as expressing 'complementary rather than contradictory' points of view which results in a 'quite different usage' (idem). This is correct in the case of Turkish 'günda bir tar çalmax' (to sing a different tune everyday) and Persian (to sing a different tune everyday) equivalents as well.

3. "An idiom may be used in the source text in both its literal and idiomatic senses at the same time" (idem). The focus of attention is both on the form and meaning of an idiomatic expression since "Unless the target-language idiom corresponds to the source-language idiom both in form and in meaning, the play on idiom can't be successfully reproduced in the target text" (idem).

To illuminate the case an Azeri example is released. There is the idiom 'yorqâniva gôra qičivi ŭzat' (Literally: crane your leg as long as your blanket) which is the same as 'don't bite off more that you can chew' in English. Also the Persian equivalent for this idiom is "إنو از كليم خودت درازتر نكن" (Literally: don’t crane your leg more than your rug). Now if the Azeri one changes the form of its idiom for some textual reasons into yorqâniva gôra qicivivi üzat yoxsa viralar qicin sinar' (crane your leg as long as your blanket or else people will break your leg), then there will be some problems for recreating the same form and meaning in the TL specially in the case of the English one which doesn't have even a word in common with both the Azeri and Persian ones. As a result the translator will be forced to give some explanatory information to 'compensate' this 'loss'. Although imperfect, but the Persian one can reproduce a

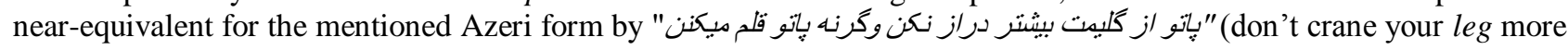
than your rug or else people will bruise your leg). The reason for this phenomenon is that in this case both Azeri and Persian have got a similar 'ideology' or 'way of thinking' that includes 'leg and blanket or rug' as well as the concept 'injury' in their worldview which permits them such plays with the roles of words and meanings. On the other hand the English idiom can not accept such role plays and modulations for its 'ideology' and 'socio-linguistic' aspects are different from the Turkish and Persian ones in this typical example.

4. "The very convention of using idioms in written discourse, the contexts in which they can be used, and their frequency of use may be different in the source and target languages" (Baker, 1992, p. 70).

All languages have got some 'rhetorical' formulae which belong merely to their own language. These rhetorical aspects of languages differ from each other. For instance while a language may use a high number of honorifics in its pronominal system as a rhetorical means, another language may make a vivid distinction between the written and spoken discourse where the written form is regarded as more formal than the spoken mode. A good example for this case includes such languages as Turkish and Persian in which the written mode is considered with a high level of formality ignoring some informal and spoken idioms as a rule. To shed light on this issue an example is given: "مثل آب "خوردن" and 'sŭ ičim' (Literally: like drinking water; Implied meaning: very easily) are two highly informal idioms respectively in Turkish and Persian and both languages use these idioms in informal contexts and especially in the spoken form but they ignore using such cases in the formal written mode. Instead they may use "خبلى ساده" or 'cox rahat' (very easy) in such formal and written modes.

In this regard Fernando and Flavell (1981, p. 85) mention that:

"Translation is an exacting art. Idiom more than any other feature of language demands that the translator be not only accurate but highly sensitive to the rhetorical nuances of the language" (cited in Baker, 1992, pp. 71).

To sum up, it can be said that some languages use a great number of idioms in both formal and informal contexts but as it was shown for the cases of Turkish and Persian ones, some other languages neglect using them in some formal contexts.

\section{B. Translation of Idiomatic Expressions: Strategies}


There exists a number of scholars suggesting some quasi-prescriptive strategies to cope with idiomatic expressions. We will take a brief glance at Gottlieb's (1997) suggestions and then elaborate on Baker's (1992) four strategies as well.

Gottlieb (1997, p. 317) states that if the translator considers the original structure and element of the source text relevant for the wording of the translation, then "he must bring the reader to the text...he [the translator] brings the text to the reader" (cited in Strakšien, 2009, p. 15). This means that we mustn't always expect an idiom to be translated exactly as an idiom; there will be some modulations in some cases. The origin of such 'shifts' (Catford, 2000, pp. 143-7 cited in Munday, 2001, pp. 61-62) is embedded on some socio-linguistic, stylistic, grammatical and finally semantic factors which sometimes cause an 'idiom' not to be rendered as an equivalent 'idiom' at all.

Gottlieb suggests two possible strategies for the cases in which the translator isn't able to keep as close to the original text:

First, focus on the meaning of the original text... [in a way that] the translator opts for stylistic loyalty, recreating the verbal atmosphere of the original. Second, focus on the intended effect on the reader.... [through which] the translator opts for conceptual loyalty, aiming at adapting the original text to a new communicative situation (cited in Strakšien, 2009, p. 15)

On the other hand Baker (1992) suggests four more detailed strategies as follows:

1. 'Using an idiom of similar meaning and form' in a way that the TL idiom conveys exactly the 'same meaning' by the use of the 'same equivalent lexical items' to the SL ones. She also expresses that this kind of match can only be achieved occasionally (p. 72).

The point to be mentioned here is that the more two cultures are identical to each other the more cases of such equivalents are possible. Contrarily, if the two cultures are not similar and the cultural differences are clearly remarkable between them, then the possibility of making such equivalents for the idiomatic expressions is decreased to its lowest degree. So it can be said that when the SL and TL cultures are identical in some cases there is an 'Automatic' process of 'domestication' proposed by Venuti (1995), i.e., in some cases the idioms in the SL are domesticated in the TL without any considerable difficulty or idiosyncrasy for both of the languages have got exactly the same idioms and ideologies resulting in an automatic domestication.

The Azeri idiom 'gôzŭm sŭ iĉmir' and its Persian equivalent "حشّم آب ندى خوره" (Literally: my eye doesn't drink water!; Free $\rightarrow$ I don't think something to happen) verify the mentioned claim. Since both Azeri and Persian are spoken in Iran with a large amount of interaction between their interlocutors, so maybe it can be deduced that one of these languages has influenced the ideology of the other one in some manners resulting in an identical idiom.

Of course this doesn't mean that it is just the culture which makes such idioms. For example there are some cases where the languages have got entirely different cultures but some idioms of them are in complete concordance to each other. Take the Turkish idiom 'ăğzima sŏz qoyma' (Literally: don't put word into my mouth) and the English equivalent "don’t put words into my mouth" alongside the Persian counterpart "حرف تو دهنم نكخار" (Literally: don’t put word into my mouth) as an example. As it is seen in this case both Turkish and Persian which have got the same cultural background use the same idiom that the English non-identical culture applies.

2. 'Using an idiom of similar meaning but dissimilar form' in a way that an idiom or fixed expression in the target language has a meaning similar to that of the source idiom or expression, but consists of different lexical items (Baker, 1992, p. 74).

This means that the lexical items of the SL idioms are not kept in the TL; instead a semantic equivalent is given in the TL. For example, the Azeri expression 'qizim sənə deyirəm, galinim sən eşit!' (Literally: my daughter, I am speaking to you; my bride, you hear!) and the Persian counterpart "به درميكح تا ديوار بشنوه" (Literally: I'm speaking to the door so that the wall hears!) use different lexical items to express more or less the same idea. Both expressions convey exactly the same meaning of the English idiom 'I beat him to frighten you'.

Another example exists where the English idiom 'When you are in Rome, do as the Romans do' corresponds in meaning to the Persian"'خواهى نشوى رسوا، هم رنك جماعت شو' (Literally: if you don't want to become ignominious, change your color to the color of the rest of people!). Repeatedly in this case, both expressions convey exactly the same meaning but the constituent parts of each idiom is different from those of the other one. For this sub-category Baker (1992) compares the English 'very much at home' and the back-translated Chinese equivalent 'totally at ease' knowing them as 'parallel in meaning' (p. 74).

3. 'Translation by paraphrase'. Baker continues that:

...this is by far the most common way of translating idioms when a match cannot be found in the target language or when it seems inappropriate to use idiomatic language in the target text because of differences in stylistic preferences of the source and target languages (idem).

The first proof for this category is seen in the case of a Persian idiom "خر بالوى بام بردن!"(Literally: to take a donkey over the roof!) for which there is no equivalent in English. Since there is not such an idiom in English and it is also inappropriate to use idiomatic language for such a case, so the translator is obliged to paraphrase the overall meaning of the ST idiom and mention it in the TL in such a non-idiomatic form as: 'To put something in its wrong place'.

There is another case as well where the Persian highly informal idiom "يه تختش كمدا" (Literally: one of his/her sheets is few!) is paraphrased as: 'S/he is out of his/her mind'. Furthermore, Baker provides some relevant examples mentioning that "one may or may not find the paraphrases accurate" (ibid: 75). It means that some of the idioms may bear a 'loss' in 
some specific characteristics of their connotative meanings while being paraphrased. For instance, if we are to translate the Persian idiom"!"خرس در كوه، بوعلى سيناست" (Literally: a bear in the mountain is Avicenna!) into English, the possible paraphrase of such a culturally-bound expression would be 'the fool is wise, where there is scarcity of wisdom'. As it can be seen the humorous aspect of the SL idiom is 'lost' in the paraphrased form. Note that there might also be another equivalent with the same meaning but dissimilar form such as 'he is a trout among minnows', but repeatedly this form won't convey the same humorous aspect that the SL idiom does.

4. 'Translation by omission' (Baker, 1992, p. 77). This means that an idiom is entirely deleted in the TL because "it has no close match in the target language, its meaning cannot be easily paraphrased, or for stylistic reasons" (idem).

This strategy is done mostly in the sentence or paragraph level. The reason for this phenomenon is that when an idiomatic expression is omitted, nearly always there is a 'loss' in the meaning. To 'compensate' the resulting loss, one is obliged to mention some supplementary words in some parts of the sentence or paragraph where an omission has been done.

In order to illuminate the point let's take a glance at the following Persian sentence and its non-literal or free translation:

"ديروز تو بازار يكى دعوايى شده بود كه بياو بيين" a Persian Fixed Expression

Back-translation $\rightarrow$ "Yesterday there was a severe quarrel in bazaar".

As it can be seen the Persian expression "بيا و بيين" (Literally: come and see) has been omitted in the TL under the strategy of omission. The reason for such an affair deals largely with the stylistic possessions of both Persian and English. Instead, there is an additional word 'severe' in the translation which 'compensates' the possible 'loss' that deletion may cause to the meaning. In this regard and considering the discussion of 'compensation' Baker (1992) expresses that:

One may either omit or play down a feature such as idiomaticity at the point where it occurs in the source text and introduce it elsewhere in the target text. This strategy is not restricted to idiomaticity or fixed expressions and may be used to make up for any loss or meaning, emotional force, or stylistic effect which may not be possible to reproduce directly at a given point in the target text....Getting this level right means that your target text will feel less 'foreign' and, other factors being equal, may even pass for an original (p. 78).

\section{CONCLUSION}

Throughout different parts of the paper it was shown that there are some difficulties regarding the translation of idioms and fixed expressions. Four of such problems were mentioned as: 1) an idiom may have no equivalent in the TL; 2) an idiom may have a similar counterpart but with different meaning; 3) an idiom may be used in both its literal and idiomatic senses at the same time; and 4) the contexts in which idioms can be used are different. Analyses showed that these difficulties are encountered in different situations. Then four strategies were mentioned to solve the problems that idiomatic expressions may cause: 1) using an idiom of similar meaning and form; 2) Using an idiom of similar meaning but dissimilar form; 3) Translation by paraphrase; and 4) Translation by omission. It was shown that there is no clearcut and predefined way to cope with idiomatic expressions, but it is the situation which decides which strategy to be taken. The important roles of socio-linguistic and cultural aspects were illustrated by a number of examples proving the fact that the more two cultures and languages are identical to each other, the more easily the process of translating idiomatic expressions becomes. Another key concept to be considered is that translator must have a deep knowledge on both SL and TL so as to understand the connotative meanings of idioms and fixed expressions of the SL and then to recreate their exact counterparts in the TL.

\section{REFERENCES}

[1] Baker, M. (1992). In other words: A coursebook on translation. London and New York: Routledge.

[2] Bateni. M. R. (2006). The living English-Persian dictionary. Tehran: Farhang Moaser Publishers. (Pouya)

[3] Belfaqeeh, N. (2009). Strategies for translating idioms and culturally-bound expressions within the human development genre. M.A. dissertation, University of Birmingham. http://www.cels.bham.ac.uk/resources/essays/Noor_Balfaqeeh_822875Diss.pdf (accessed 12/02/2011)

[4] Bentivogli, L. \& Pianta, E. (no date). Looking for lexical gaps. http://multiwordnet.fbk.eu/paper/wordnet-euralex2000.pdf (accessed 15/02/2011)

[5] Carter, R. (1998). Vocabulary: Applied Linguistics Perspectives (2nd edin). London and New York: Routledge,

[6] Changizian, F. (2004). The world of Persian and English idioms. Qom: Nilufaraneh Publications

[7] Chomsky, N. (1957). Syntactic structures. Gravenhage: Mouton.

[8] Fernando, C. (1994). Idioms and idiomaticity. Oxford: Oxford University Press.

[9] Fernando, C. \& Flavell, R. (1981). On idiom: Critical views and perspectives (Exter Linguistic Studies 5, University of Exeter), Chapter 4, 'Contrastive Ideology'.

[10] Haghshenas, A. M. Samei, H. \& Entekhabi, N. (2003). One Volume Millennium English-Persian Dictionary. Tehran: Farhang Moaser Publishers. (Hezaareh)

[11] Hartmann, R \& James, G. (2002). Dictionary of lexicography. London and New York: Routledge.

[12] Hatim, B. \& Mayson, I. (1990). Discourse and the translator. London and New York: Longman

[13] Hatim, B. \& Mayson, I. (1997). The translator as communicator. London and New York: Routledge. 
[14] Larson, M. (1984). Meaning-based translation: A guide to cross-language equivalents. Lanham: University Press of America.

[15] McMordiew, J. S. (1983). English idioms and how to use them. Moscow: Vyschaja shkola.

[16] Miremadi, A. (1993). Theories of translation and interpretation. Tehran: SAMT

[17] Munday, J (2001). Introducing Translation Studies: Theories and Applications.USA and Canada: Routledge.

[18] Moon, R. (1998). Fixed expressions and idioms in English: A corpus-based approach. Oxford: Clarendon Press.

[19] Nida, E. A. (1964). Toward a science of translating. Leiden: E. J. Brill.

[20] Newmark, P. (1988). A textbook of translation. New York: TiceHall Press.

[21] Strakšiene, M. (2009). Analysis of idiom translation strategies from English into Lithuanian. STUDIES ABOUT LANGUAGES. NO. 14, 13-19. http://www.kalbos.lt/zurnalai/14_numeris/03.pdf (accessed 07/03/2011)

[22] Summers, D. (2003). Longman dictionary of contemporary English. London: Pearson Education Ltd.

[23] Trrefry, D. (ed.) (2006). Collins English Dictionary. Glasgow, UK: HarperCollins Publishers

[24] Venuti, L. (2000). The Translation Studies Reader. UK: Routledge.

[25] Watson, D. (1991). Practicing idioms. Hong Kong: Nelson

[26] Wehmeier, S. (2000). Oxford advanced learner's Dictionary. Oxford: Oxford University Press.

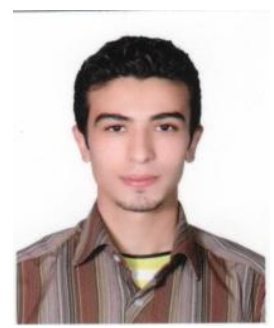

Amir Shojaei was born in Tabriz, Iran on September 5, 1987. He is an M.A. student of Translation Studies in Azad University of Quchan, Iran. He lives in Tabriz and received his B.A. in the field from Azad University of Tabriz, Iran in 2009. Besides teaching various courses of EFL at some English institutes, he does some practical translational affairs from English to Persian for a number of newspapers largely including political and journalistic texts. 